\title{
Does Global Warming Cause Intensified Interannual Hydroclimate Variability?*
}

\author{
RiCHARD SEAGER AND NAOMI NAIK \\ Lamont Doherty Earth Observatory, Columbia University, Palisades, New York \\ LAURA VOGEL \\ Columbia College, New York, New York
}

(Manuscript received 27 June 2011, in final form 18 October 2011)

\begin{abstract}
The idea that global warming leads to more droughts and floods has become commonplace without clear indication of what is meant by this statement. Here, the authors examine one aspect of this problem and assess whether interannual variability of precipitation $P$ minus evaporation $E$ becomes stronger in the twenty-first century compared to the twentieth century, as deduced from an ensemble of models participating in Coupled Model Intercomparison Project 3. It is shown that indeed interannual variability of $P-E$ does increase almost everywhere across the planet, with a few notable exceptions such as southwestern North America and some subtropical regions. The variability increases most at the equator and the high latitudes and least in the subtropics. Although most interannual $P-E$ variability arises from internal atmosphere variability, the primary potentially predictable component is related to the El Niño-Southern Oscillation (ENSO). ENSOdriven interannual $P-E$ variability clearly increases in amplitude in the tropical Pacific, but elsewhere the changes are more complex. This is not surprising in that ENSO-driven $P-E$ anomalies are primarily caused by circulation anomalies combining with the climatological humidity field. As climate warms and the specific humidity increases, this term leads to an intensification of ENSO-driven $P-E$ variability. However, ENSOdriven circulation anomalies also change, in some regions amplifying but in others opposing and even overwhelming the impact of rising specific humidity. Consequently, there is sound scientific basis for anticipating a general increase in interannual $P-E$ variability, but the predictable component will depend in a more complex way on both thermodynamic responses to global warming and on how tropically forced circulation anomalies alter.
\end{abstract}

\section{Introduction}

According to projections with climate models, global warming driven by rising greenhouse gas concentrations will cause significant changes in the distribution of precipitation $P$ minus evaporation $E$ at the earth's surface. These can be summarized as dry areas getting drier and wet areas getting wetter and a poleward and equatorward expansion of the subtropical dry zones. These changes arise from intensified atmospheric moisture transports in a warmer, more moist atmosphere and a

* Lamont Doherty Earth Observatory Contribution Number 7519.

Corresponding author address: Richard Seager, Lamont Doherty Earth Observatory, Columbia University, 61 Route 9W, Palisades, NY 10964

E-mail: seager@ldeo.columbia.edu poleward expansion of Hadley Cell, poleward shift of the midlatitude storm tracks, and equatorward contraction of convergence zones (Held and Soden 2006; Seager et al. 2007; Neelin et al. 2006; Chou et al. 2009; Seager et al. 2010c). These changes in $P-E$ will create problems in water-stressed arid zones as well as add to flooding hazards in regions expected to get wetter. However, natural climate variability on day-to-day, month-to-month, year-to-year, and decade-to-decade time scales already causes havoc in terms of agricultural losses, transportation disruption by storms, shortfalls in municipal water supply, flooding in low-lying areas, death by starvation following disrupted food availability or in heat waves, and so on. Recent examples of disruption, suffering, and death caused by climate events that, if not entirely unsullied by the influence of anthropogenic climate change, contain a large component of natural climate variability are the intensely cold and snowy 2009/10 winter in the eastern United States 
and northwest Europe (Seager et al. 2010b; Cattiaux et al. 2010), the Pakistan floods (Webster et al. 2011) and Russian heat wave (Dole et al. 2011) of summer 2010, the intense flooding in northeast Australia early in 2011, and the China drought of winter 2010/11. Although it is clearly important to develop means to adapt to long-term climate trends, a strong case can be made that developing resilience to the worst challenges that natural climate variability can pose will, in and of itself, create a basic level of resilience to anthropogenic climate change (Sarachik 2010). Indeed, for countries such as Pakistan, where whole communities were washed away in the 2010 monsoon floods, it makes little sense to adapt to a multidecadal time-scale trend when the countries' infrastructure is so severely stressed by already-existing (dominantly natural) year-to-year variability.

As Sarachik (2010) says, mitigation addresses climate trends, but adaptation is about climate variability. However, this does not let climate change off the hook in terms of adaptation. There is a growing sense that a purely natural (i.e., uninfluenced by human activity) climate system no longer exists, and it is widely assumed that climate events like heat waves, stormy winters, droughts, and floods bear at least some imprint of human-induced climate change, rendering the term "natural climate variability" a relic of the preindustrial age. It is commonly stated, for example, that global warming will simultaneously lead to more floods and droughts and more climate extremes. As a fairly typical example of common assumptions, writing in the New York Times on 15 August 2010, Justin Giles stated, "Theory suggests that a world warming up...will feature heavier rainstorms in summer, bigger snowstorms in winter, more intense droughts in at least some places and more record-breaking heat waves." That is, global warming will lead to more extreme climate variability on all time scales.

Increases in atmospheric humidity associated with warming provide a rationale for these assumptions: any given circulation anomaly can draw on more moisture than before and create more precipitation. This argument is used to explain observed increases in the proportion of total precipitation falling in the most intense events (Trenberth et al. 2003; Groisman et al. 2005), although to our knowledge proof of this assertion has not yet been forthcoming. However, if this is so on short time scales of days or less, the same process should work on interannual time scales. For example, El Niño-Southern Oscillation (ENSO)-related $P-E$ anomalies and tropical Pacific forced decadal precipitation changes are fundamentally driven by changes in circulation acting on the climatological humidity field (Huang et al. 2005; Seager 2007; Seager and Naik 2012, hereafter SN12) (and below). As specific humidity rises these same forced circulation anomalies should cause more intensified $P-E$ variability and hence more extreme droughts and floods.

However, does interannual $P-E$ variability intensify as climate warms? Given that interannual $P-E$ variability is forced by circulation anomalies, it is possible that changes in SST variability or atmosphere dynamics could also create changes in $P-E$ variability that offset or maybe amplify the expected increase due to thermodynamic processes alone. Although adaptation to climate variability is a good first step toward adaptation to climate change, it needs to be known what climate variability to adapt to. Most countries in the world are already stressed by climate variability [including wealthy ones with well-developed infrastructure, as evidenced by, e.g., drought in the southeast United States in 2006/07 (Seager 2007) and floods in the United Kingdom in 2000 (Pall et al. 2011)], and if global warming causes the variability to get more extreme this needs to be known. That is what we examine here, focusing on the year-to-year time scale. On this time scale, the dominant mode of global $P-E$ variability is ENSO. We will examine the Coupled Model Intercomparison Project 3 (CMIP3) archive used by the Intergovernmental Panel on Climate Change (IPCC) Fourth Assessment Report 4 (AR4) (Meehl et al. 2007) using simulations of the twentieth century and projections of the current century in all the models that make all the needed data available. We will look at how ENSO-related $P-E$ variability changes and separate this into changes in the dynamic (caused by circulation anomalies) and thermodynamic (caused by humidity anomalies) components and then look at how these contributions change between the centuries and, to the extent we can, why.

Increased amplitude of interannual variability as a consequence of global warming would create new problems for societies struggling to adapt to already-existing interannual variability. This would be in addition to any additional challenges posed by trends in the mean climate state and, on the floods side, changes in land use and population within the catchment and flood plains. As we will show, model projections of current-century climate show a widespread but not universal increase in the amplitude of the total interannual variability of $P-E$ and of the ENSO-driven component in many places. However, in some regions changes in circulation variability offset changes due to increasing humidity leading to little change in or even reduced amplitude of $P-E$ variability.

\section{Model data used and methodology}

We analyze 19 models from the CMIP3-IPCC AR4 archive. The models were selected because all of the 
needed data were available and free of errors. We analyze both the twentieth-century simulations with known and estimated past climate forcings and the projections of twenty-first century climate using the "middle of the road" Special Report on Emission Scenarios (SRES) A1B emissions scenario. In prior work (Seager et al. 2010a; SN12), we have analyzed only those models and time periods for which all the daily data needed to evaluate transient eddy moisture convergences were available (1961-2000 and 2046-65). SN12) showed that ENSOforced $P-E$ variability is dominated in these CMIP3IPCC AR4 models by changes in the mean circulation combining with the climatological moisture field to create anomalous convergence and divergence of moisture. They found that contributions from both variability in humidity and changes in moisture convergence or divergence by transient eddies (defined as covariances of submonthly wind and specific humidity fields) were decidedly of secondary importance. Here, we do not seek to evaluate changes in the variability of transient eddy moisture convergence and divergence, which means we do not need daily data. This allows us to improve the characterization of contributions to $P-E$ variability from changes in mean quantities by using the entire two centuries of modeled data and allows an expansion from 15 to 19 models. Of the 24 CMIP3-IPCC AR4 models available, 5 were not used; 3 because of lack of needed data and 2 because their natural variability was blatantly unrealistic. Included and excluded models are listed in Table 1.

We begin with the vertically integrated moisture budget equation, which balances $P-E$ with convergence of moisture by the mean and transient flow: namely,

$$
\begin{aligned}
\rho_{w} g(\bar{P}-\bar{E}) \approx & -\int_{0}^{\bar{p}_{s}}(\nabla \cdot(\overline{\overline{\mathbf{u}}} \overline{\bar{q}}+\overline{\overline{\mathbf{u}}} \hat{q}+\hat{\mathbf{u}} \overline{\bar{q}}) d p \\
& -\int_{0}^{\bar{p}_{s}} \nabla \cdot\left(\overline{\left(\overline{\mathbf{u}^{\prime} q^{\prime}}\right.}\right) d p-\overline{q_{s} \mathbf{u}_{s} \cdot \nabla p_{s}} .
\end{aligned}
$$

Here, $E$ is understood to be evaporation over the ocean and evapotranspiration over land. In Eq. (1), the climatological monthly-mean quantities are represented by double overbars, monthly means are represented by single overbars, monthly departures from the climatological monthly mean are represented by hats, and departures from monthly means are represented by primes. Total fields are given by, for example, $\mathbf{u}=\overline{\mathbf{u}}+\mathbf{u}^{\prime}=\overline{\overline{\mathbf{u}}}+\hat{\mathbf{u}}+\mathbf{u}^{\prime}$. Products of monthly anomalies have been neglected. The $\rho_{w}$ is water density, $g$ is the acceleration due to gravity, $p$ is pressure, $p_{s}$ is surface pressure, $\mathbf{u}$ is the horizontal vector wind and $\mathbf{u}_{\mathbf{s}}$ is its surface value, and $q$ is specific humidity. The first term on the right-hand side is the horizontal moisture convergence by the mean flow, and the second term is the horizontal moisture convergence by the submonthly transient eddies. [The third term provides a general tendency to reduce $P-E$ (because of surface flow down the pressure gradient) but cannot be evaluated for all models because many did not save daily values of surface winds and humidity. Within the Geophysical Fluid Dynamics Laboratory Climate Model version 2.1 (GFDL CM2.1), this term was evaluated with daily data and then found to be reasonably approximated using monthly data. We then evaluated it for all models using monthly data. It is several times smaller than the other two terms, and we discuss it no more.]

The dominant mode by far of global $P-E$ variability is ENSO. Hence, we will focus on potential changes in the interannual variability of ENSO-forced $P-E$ variability. We break down the moisture budget into a term related to variability in circulation and a term related to variability in humidity, variability in transient eddy moisture convergence, and variability in the boundary term. We introduce the notation

$$
\langle\mathbf{A}\rangle^{T}=\int_{0}^{\overline{\bar{p}}_{s}, T}(\boldsymbol{\nabla} \cdot \mathbf{A}) d p .
$$

The superscript $T$ indicates the time period (i.e., twentieth or twenty-first century) corresponding to the pressure data for the vertical integral. Below the subscript $T$ indicates a time period for the subscripted variable. Then we have for the case of ENSO variability,

$$
\begin{aligned}
\rho_{w} g \delta(\bar{P}-\bar{E}) & \approx \delta \mathrm{TH}+\delta \mathrm{MCD}+\delta \mathrm{TE}-\delta S, \\
\delta \mathrm{TH} & =-\delta\left\langle\overline{\mathbf{u}}_{T} \hat{q}_{T}\right\rangle^{T}, \\
\delta \mathrm{MCD} & =-\delta\left\langle\hat{\mathbf{u}}_{T} \overline{\bar{q}}_{T}\right\rangle^{T}, \\
\delta \mathrm{TE} & =-\delta\left\langle\left(\overline{\left(\overline{\mathbf{u}}^{\prime} q^{\prime}\right.}\right)_{T}\right\rangle^{T}, \quad \text { and } \\
\delta S & =\delta\left(\overline{q_{S} \mathbf{u}_{s} \cdot \nabla p_{s}}\right)_{T} .
\end{aligned}
$$

The term influenced only by changes in humidity is called the thermodynamic term $\delta \mathrm{TH}$ and the term influenced only by changes in the mean circulation is called the dynamic term $\delta \mathrm{MCD}$. Here, $\delta \mathrm{TE}$ is the term related to changes in transient eddy fluxes and $\delta S$ is the change in the boundary term. The difference $\delta$ is given by

$$
\delta(\cdot)=[\cdot]_{\mathrm{LN}}-[\cdot]_{\mathrm{EN}},
$$

where the square brackets with subscripts LN and EN indicate time averaging over months with La Niña or El Niño conditions of the quantity in parentheses. The approximate equality in Eq. (3) assumes that the vertically integrated climatological term is the same averaged over El Niño events as over La Niña events, despite 
TABLE 1. Information on models considered for this study.

\begin{tabular}{|c|c|c|c|c|}
\hline \multicolumn{5}{|c|}{ Included models } \\
\hline & Model name & Country & $\begin{array}{l}\text { Atmospheric } \\
\text { resolution }\end{array}$ & $\begin{array}{c}\text { Run No. } \\
\text { 20C3M/SRES A1B }\end{array}$ \\
\hline 1 & $\begin{array}{l}\text { Bjerknes Centre for Climate Research } \\
\text { Bergen Climate Model version } 2 \\
\text { (BCCR-BCM2) }\end{array}$ & Norway & $\mathrm{T} 63$ & run1/run1 \\
\hline 2 & $\begin{array}{l}\text { Canadian Centre for Climate Modelling } \\
\text { and Analysis (CCCma) Coupled } \\
\text { General Circulation Model, } \\
\text { version 3.1 (CGCM3.1) T47 }\end{array}$ & Canada & $\mathrm{T} 47$ & run1/run1 \\
\hline 3 & CGCM3.1 T63 & Canada & T63 & run1/run1 \\
\hline 4 & $\begin{array}{l}\text { Centre National de Recherches } \\
\text { Météorologiques Coupled Global } \\
\text { Climate Model, version } 3 \\
\text { (CNRM-CM3) }\end{array}$ & France & T63 & run1/run1 \\
\hline 5 & $\begin{array}{l}\text { Commonwealth Scientific and } \\
\text { Industrial Research Organisation } \\
\text { Mark version } 3 \text { (CSIRO Mk3.0) }\end{array}$ & Australia & T63 & run1/run1 \\
\hline 6 & $\begin{array}{l}\text { Geophysical Fluid Dynamics Laboratory } \\
\text { Climate Model version } 2.0 \\
\text { (GFDL CM 2.0) }\end{array}$ & United States & $2.5^{\circ} \times 2^{\circ}$ & run1/run1 \\
\hline 7 & GFDL CM2.1 & United States & $2.5^{\circ} \times 2^{\circ}$ & run1/run1 \\
\hline 8 & $\begin{array}{l}\text { National Aeronautics and Space } \\
\text { Administration (NASA) Goddard } \\
\text { Institute for Space Studies } \\
\text { Model E-H (GISS-EH) }\end{array}$ & United States & $5^{\circ} \times 4^{\circ}$ & run1/run1 \\
\hline 9 & NASA GISS-ER & United States & $5^{\circ} \times 4^{\circ}(\mathrm{B}$ grid $)$ & run1/run2 \\
\hline 10 & $\begin{array}{l}\text { State Key Laboratory of Numerical } \\
\text { Modeling for Atmospheric Sciences } \\
\text { and Geophysical Fluid Dynamics } \\
\text { (LASG) Flexible Global } \\
\text { Ocean-Atmosphere-Land System } \\
\text { Model gridpoint version } 1.0 \\
\text { (FGOALS-g1.0) }\end{array}$ & China & $\mathrm{T} 42$ & run1/run2 \\
\hline 11 & $\begin{array}{l}\text { Istituto Nazionale di Geofisica e } \\
\text { Vulcanologia (INGV) ECHAM4 }\end{array}$ & Italy & T106 & run1/run1 \\
\hline 12 & $\begin{array}{l}\text { Institute of Numerical Mathematics } \\
\text { Coupled Model, version } 3 \\
\text { (INM-CM3) }\end{array}$ & Russia & $5^{\circ} \times 4^{\circ}$ & run1/run1 \\
\hline 13 & $\begin{array}{l}\text { L'Institut Pierre-Simon Laplace } \\
\text { Coupled Model, version } 4 \\
\text { (IPSL CM4) }\end{array}$ & France & $2.5^{\circ} \times 3.75^{\circ}$ & run1/run1 \\
\hline 14 & $\begin{array}{l}\text { National Institute of Environmental } \\
\text { Studies (NIES) Model for } \\
\text { Interdisciplinary Research on } \\
\text { Climate 3.2, high-resolution } \\
\text { version [MIROC3.2(hires)] }\end{array}$ & Japan & $\mathrm{T} 42$ & run2/run1 \\
\hline 15 & NIES MIROC3.2(medres) & Japan & T106 & run1/run1 \\
\hline 16 & $\begin{array}{l}\text { Max Planck Institute (MPI) } \\
\text { ECHAM5-MPI-OM }\end{array}$ & Germany & T63 & run1/run1 \\
\hline 17 & $\begin{array}{l}\text { Meteorological Research Institute } \\
\text { Coupled General Circulation } \\
\text { Model, version 2.3.2 } \\
\text { (MRI CGCM2.3.2) }\end{array}$ & Japan & $\mathrm{T} 42$ & run1/run1 \\
\hline 18 & $\begin{array}{l}\text { National Center for Atmospheric } \\
\text { Research (NCAR) Community } \\
\text { Climate System Model, version } \\
2 \text { (CCSM3) }\end{array}$ & United States & $\mathrm{T} 85$ & run1/run1 \\
\hline 19 & $\begin{array}{l}\text { Met Office (UKMO) Hadley Centre } \\
\text { Global Environmental Model } \\
\text { version } 1 \text { (HadGEM1) }\end{array}$ & United Kingdom & $1.875^{\circ} \times 1.25^{\circ}$ & run1/run1 \\
\hline
\end{tabular}


TABLE 1. (Continued)

\begin{tabular}{lll}
\hline \hline \multicolumn{1}{c}{ Model name } & \multicolumn{1}{c}{ Excluded models } \\
\hline CSIRO Mk3.0 & \multicolumn{1}{c}{ Country } & Problem with data \\
$\begin{array}{l}\text { NASA GISS-Atmosphere-Ocean } \\
\text { Model (GISS-AOM) }\end{array}$ & Australia & No $p_{s}$ for twenty-first century \\
ECHAM and the global Hamburg & United States & Natural variability in twenty-first century is unrealistic \\
Ocean Primitive Equation (ECHO-G) & Germany/South Korea & No monthly $q, u$, or $v$ \\
NCAR Parallel Climate Model 1 (PCM1) & United States & Unrealistic ENSO variability in Indian Ocean \\
$\begin{array}{l}\text { UKMO third climate configuration of the } \\
\text { Met Office Unified Model (HadCM3) }\end{array}$ & United Kingdom & No $q$ for twenty-first century \\
\end{tabular}

the differing limits on the pressure integral; that is, $\left[\left\langle\overline{\mathbf{u}}_{T} \overline{\bar{q}}_{T}\right\rangle^{T}\right]_{\mathrm{EN}} \approx\left[\left\langle\overline{\overline{\mathbf{u}}}_{T} \overline{\bar{q}}_{T}\right\rangle^{T}\right]_{\mathrm{LN}}$.

El Niño and La Niña conditions are found by conducting an empirical orthogonal function (EOF) analysis of the annual-mean $P-E$ field in each model and for each century, after detrending to remove the centurylong trends. Because ENSO events tend to be centered on the boreal winter season, the annual mean is defined on a July-June year. Defining ENSO using $P-E$ is unorthodox but makes sense in that $P-E$, rather than ocean temperature, is our interest here. The $P-E$ variance is also concentrated in the tropics, and hence ENSO variability is easily located in this manner. Indeed, in all models the first EOF is the model's representation of ENSO, centered in the tropical Pacific and explaining between $15 \%$ and $49 \%$ of the total variance of $P-E$ with a mean of $32 \%$, comparable to that observed (see SN12). To compute La Niña minus El Niño differences, we take the associated principal component for each model and compute composites over all years when it exceeds one standard deviation and all years when it is below one standard deviation. This difference is the La Niña minus El Niño composite difference. Here, we only show the multimodel ensemble mean (MEM) of the composite differences.

To analyze the change in the $P-E$ variability, we will need to determine what causes twentieth-century to twenty-first century changes in the MCD and TH contributions: that is, how changes in the mean and variability of specific humidity and circulation cause changes in the dynamic and thermodynamic drivers of $P-E$ variability. To do this, we define a twenty-first-century minus twentiethcentury change as

$$
\Delta(\cdot)=(\cdot)_{21}-(\cdot)_{20},
$$

where the subscripts 21 and 20 refer to twenty-first-century and twentieth-century averages. Hence, $\overline{\mathbf{u}}_{21}=\overline{\mathbf{u}}_{20}+\Delta \overline{\mathbf{u}}$, $\delta \bar{q}_{21}=\delta \bar{q}_{20}+\Delta \delta \bar{q}$, etc. Hence, the change in $P-E$ variability can be divided up into changes in the variabilities of the thermodynamic term, the mean circulation dynamics term, and the transient eddy and boundary terms: namely,

$$
\begin{aligned}
\rho_{w} g \Delta[\delta(P-E)] \approx & \Delta(\delta T H)+\Delta(\delta M C D) \\
& +\Delta(\delta T E)-\Delta(\delta S) .
\end{aligned}
$$

Substituting the relations for twenty-first-century and twentieth-century values into Eq. (3) and neglecting terms nonlinear in $\Delta$ (such as $\Delta \overline{\mathbf{u}} \Delta \bar{q})$ gives

$$
\begin{aligned}
\Delta(\delta \mathrm{TH}) & \approx \Delta\left(\delta \mathrm{TH}_{q}\right)+\Delta\left(\delta \mathrm{TH}_{u}\right), \\
\Delta\left(\delta \mathrm{TH}_{q}\right) & =-\delta\left\langle\overline{\overline{\mathbf{u}}}_{20} \Delta \hat{q}\right\rangle^{21}, \quad \text { and } \\
\Delta\left(\delta \mathrm{TH}_{u}\right) & =-\delta\left\langle\Delta \overline{\overline{\mathbf{u}}} \hat{q}_{20}\right\rangle^{21} ;
\end{aligned}
$$

that is, the change in the thermodynamic contribution to $P-E$ variability involves a term [Eq. (12)] that is caused by a change in the humidity variability combining with the unchanged circulation and a term [Eq. (13)] that is caused by a change in the mean circulation combining with the unchanged humidity variability. The approximation in Eq. (11) assumes that $\delta\left\langle\overline{\mathbf{\mathbf { u }}}_{20} \hat{q}_{20}\right\rangle^{21} \approx \delta\left\langle\overline{\overline{\mathbf{u}}}_{20} \hat{q}_{20}\right\rangle^{20}$, which was assessed and found to be valid.

Similarly, the mean circulation dynamics contribution to the change in $P-E$ variability breaks down as

$$
\begin{aligned}
\Delta(\delta \mathrm{MCD}) & \approx \Delta\left(\delta \mathrm{MCD}_{q}\right)+\Delta\left(\delta \mathrm{MCD}_{u}\right), \\
\Delta\left(\delta \mathrm{MCD}_{q}\right) & =-\delta\left\langle\hat{\mathbf{u}}_{20} \Delta \overline{\bar{q}}\right\rangle^{21}, \text { and } \\
\Delta\left(\delta \mathrm{MCD}_{u}\right) & =-\delta\left\langle\Delta \hat{\mathbf{u}} \overline{\bar{q}}_{20}\right\rangle^{21}:
\end{aligned}
$$

that is, a term [Eq. (15)] caused by the change in mean humidity combining with the unchanged circulation variability and a term [Eq. (16)] caused by a change in the circulation variability combining with the unchanged humidity. The approximation in Eq. (14) assumes that 
$\delta\left\langle\hat{\mathbf{u}}_{20} \overline{\bar{q}}_{20}\right\rangle^{21} \approx \delta\left\langle\hat{\mathbf{u}}_{20} \overline{\bar{q}}_{20}\right\rangle^{20}$, which was also assessed and found to be valid.

At this point, it should be noticed that the breakdown of $P-E$ variability into thermodynamic and dynamic contributions is no longer absolute. As climate changes and climatological-mean specific humidity and circulation change, the efficiency of the thermodynamic and dynamic contributions to $P-E$ variability will change. For example, $P-E$ variability that arises from specific humidity variability will differ as the climatological-mean circulation that converges the humidity anomalies changes. Similarly, the increase in climatological-mean specific humidity accompanying global warming appears in the $\Delta\left(\mathrm{MCD}_{q}\right)$ term, where it acts to make the circulation variability more effective: that is, the same amplitude of circulation variability in the twenty-first century as in the twentieth century creates a tendency to larger $P-E$ variability because it is operating on an enhanced-mean moisture field.

\section{Changes in model simulated total interannual $\boldsymbol{P}-\boldsymbol{E}$ variability}

Although the remainder of the paper considers changes in $P-E$ variability associated with the leading mode of global $P-E$ variability, ENSO, we begin with an assessment of how the total $P-E$ variability changes. Figure 1 shows the MEM of the variances of annual-mean $P-E$ of each model for the entire simulated twentieth century, the projected twenty-first century, and the difference. In this case, the $P-E$ variability is contributed to by ENSO, all other large-scale modes of $P-E$ variability in the models (e.g., model representations of Atlantic variability, Indian Ocean sector variability, decadal Pacific variability, the North Atlantic Oscillation, annular modes, etc.), and the smaller-scale and higher-frequency variability often referred to as "noise" in the climate research literature but commonly considered to be weather. There is a clear increase of interannual $P-E$ variability over the tropical Pacific Ocean where ENSO originates. That is, the difference between the positive El Niño anomalies and negative La Niña anomalies becomes larger in the twenty-first century as the climate warms. The percent change in total variance is shown in Fig. 2a. An increase in variance occurs across almost the entire planet, with maximum increases in the tropical Pacific and the polar regions. There are regions of decrease over southern North America, Central America, the subtropical Atlantic Ocean, the equatorial Atlantic Ocean, and northeast Brazil and over parts of the subtropical eastern Pacific Ocean. In addition, there is a clear spatial structure to the change in variance with the largest increases in the equatorial Pacific Ocean and polar regions
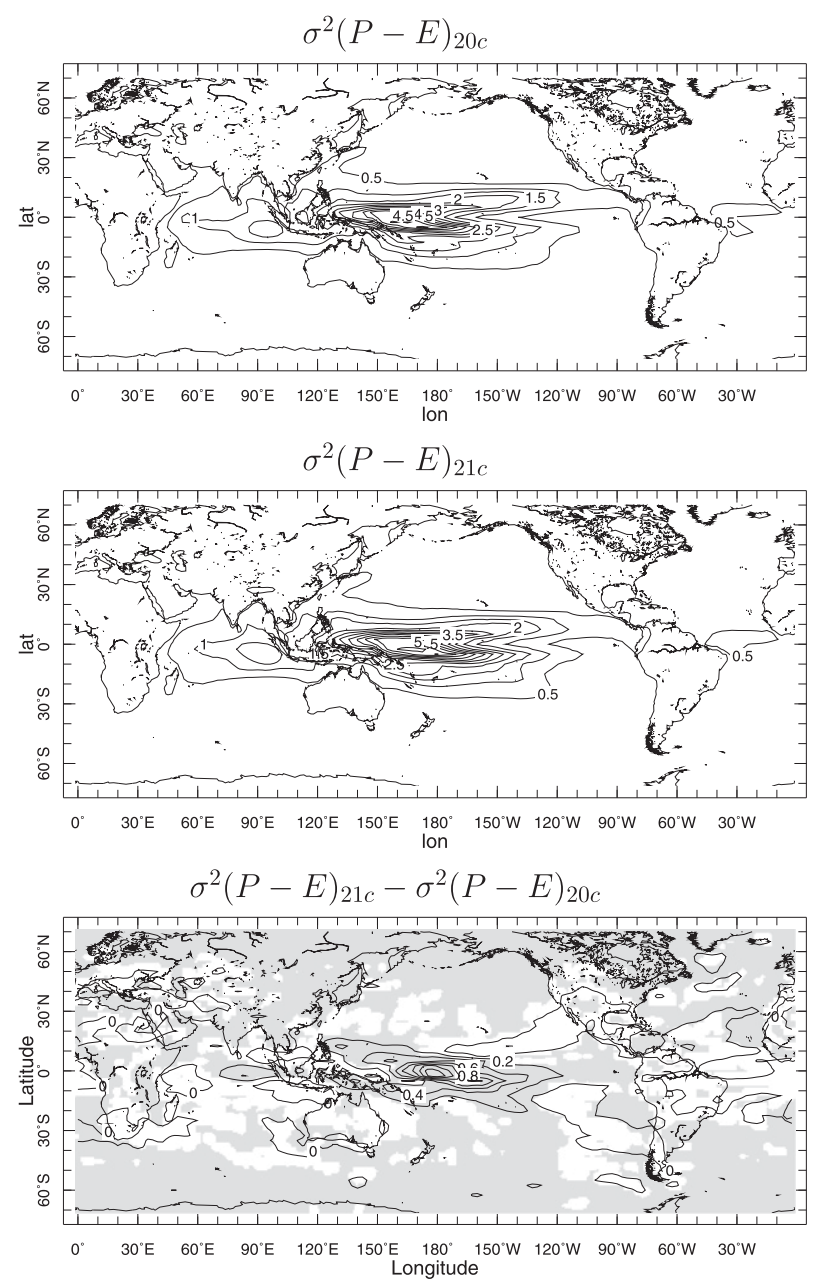

FIG. 1. The variance of annual-mean $P-E$ for (top) the twentieth century, (middle) the twenty-first century, and (bottom) the difference evaluated for each model and then averaged across the multimodel ensemble. Shading in (bottom) indicates significance at the $95 \%$ level. Units are $\left(\mathrm{mm} \mathrm{day}^{-1}\right)^{2}$.

and, in general, lesser increases, or decreases, in the subtropics.

The most obvious likely cause of a general increase in $P-E$ variability is the increase in the climatologicalmean specific humidity, which will allow even unchanged circulation anomalies to create larger moisture convergence anomalies. The fractional change in the vertically integrated lower-tropospheric specific humidity is shown in Fig. 2b. It increases everywhere and has generally the same spatial structure as the increase in $P-E$ variance with tropical and high-latitude maxima and subtropical minima. The pattern of change in lower-tropospheric water vapor is akin to that of the change in mean $P-E$ that accompanies global warning (Held and Soden 2006; Seager et al. 2010c). 


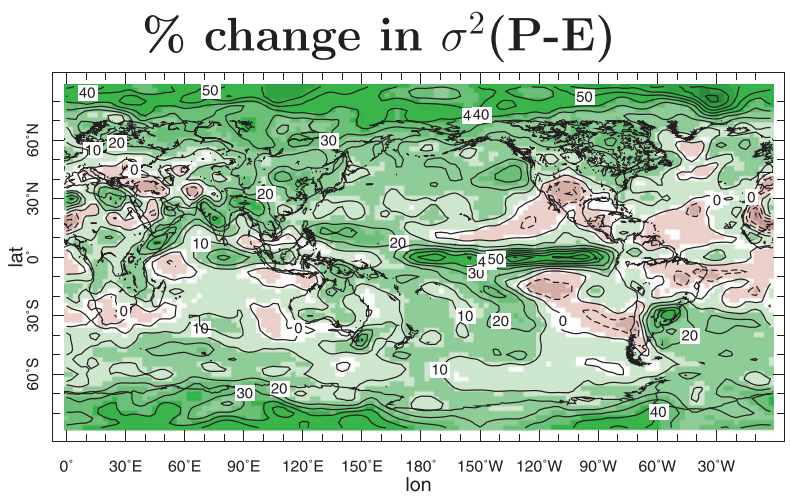

\section{$\%$ change in moisture, $1000 \mathrm{mb}$ to $700 \mathrm{mb}$}
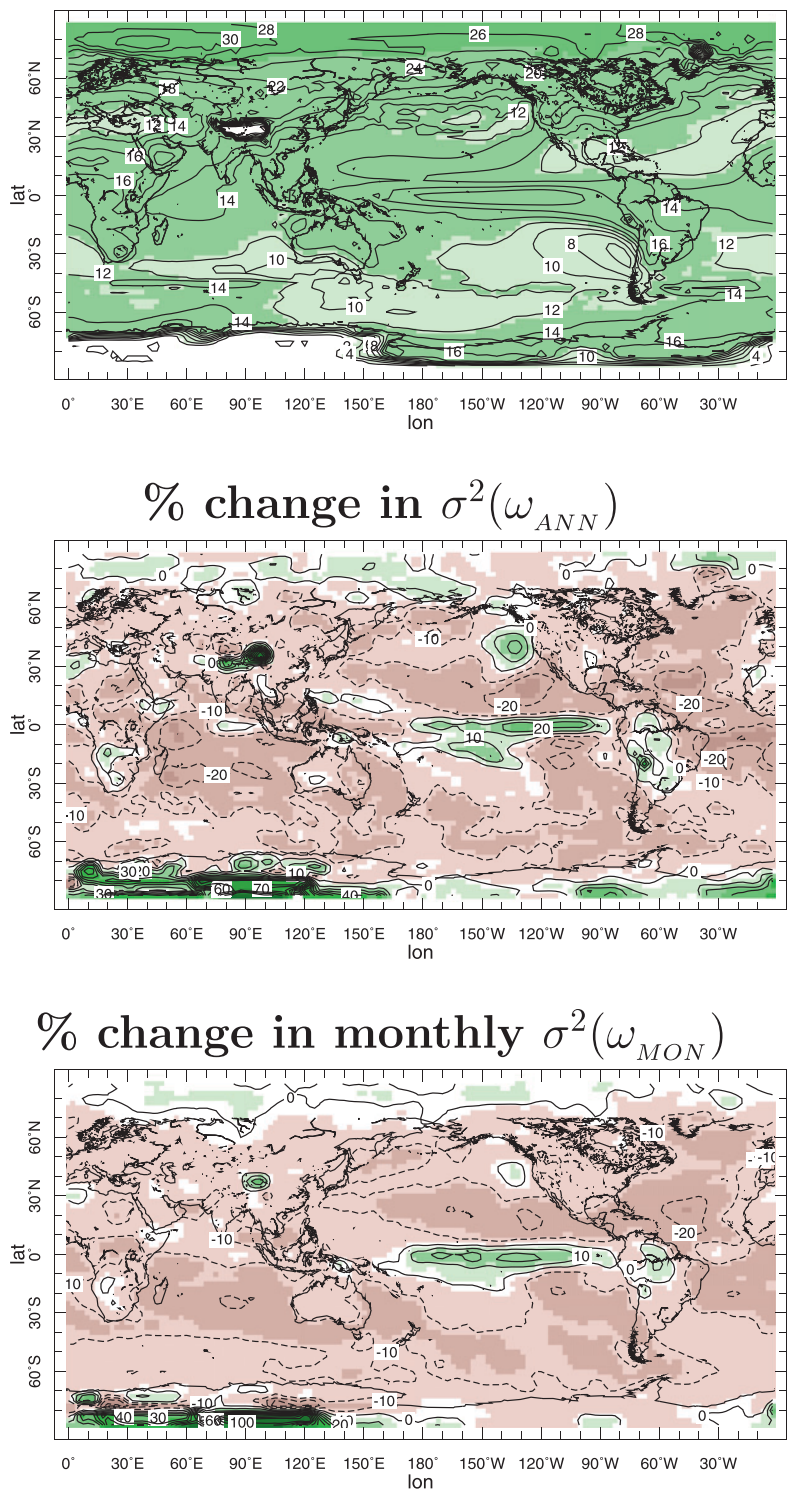

FIG. 2. (top) The percent change in variance of the annual-mean $P-E$ field, (top middle) the percent change in the vertically integrated specific humidity, and the percent changes in (bottom middle) annual-mean and (bottom) monthly-mean vertical velocity variance for the multimodel ensemble. 
However, comparing Figs. 2a,b, it is also clear that the increase in $P-E$ variance is in some places markedly less than the change in the mean specific humidity and in others markedly greater. In work on increases in precipitation intensity it has proven possible to provide an explanation accounting only for, say, how condensation along a moist adiabat changes as the atmosphere column warms (O'Gorman and Schneider 2009) while ignoring changes in vertical velocity. This does not appear to be the case for annual-mean $P-E$ variance. Figures $2 \mathrm{c}, \mathrm{d}$ show that the variances of both the monthly-mean and the annual-mean vertical velocities at $700 \mathrm{mb}$ decline from the twentieth century to the twenty-first century almost everywhere. Areas of increase are limited to the polar regions and the equatorial Pacific Ocean (and a few other isolated locations). Here, $P-E$ is inextricably tied to the product of vertical motion and the specific humidity of the lifted air. For the widespread areas where the $P-E$ variance changes less than the increase in mean specific humidity, it is because the vertical velocity variance decreases. Consequently, for changes in the interannual variability of $P-E$, both changes in the mean specific humidity and changes in the vertical velocity variance are important. Needless to say, the former is easily understood in terms of moist thermodynamics, whereas there is less understanding of the latter because vertical motion fields are determined through a complex mix of dynamical and thermodynamical processes and across a wide range of circulation phenomena. It should also be noted that, over land areas, unlike over the ocean, processes involving soil moisture, groundwater (if included in the model), and vegetation can influence $E$ and hence $P$ and water vapor convergence or divergence and that these land surface feedbacks can impact circulation and climate variability (e.g., Koster et al. 2004; Lo and Famiglietti 2011; Seneviratne et al. 2006; Anyah et al. 2008).

\section{Changes in ENSO-driven interannual $P-E$ variability}

We now turn our attention to that portion of the total $P-E$ variability driven by ENSO. Figure 3 shows the La Niña minus El Niño MEM mean $P-E$ pattern for the two centuries and the difference. The difference is only colored where significant at the $95 \%$ significance level using a two-sided $t$ test. The models show for both centuries the expected pattern with drying across the equatorial Pacific Ocean (but extending too far west compared to observations; e.g., Seager et al. 2005) with increased $P-E$ in the Pacific intertropical convergence zone (ITCZ) and South Pacific convergence zone (SPCZ), over the Maritime Continent and eastern Indian Ocean, and over the tropical Atlantic Ocean and tropical South
America. There is also increased $P-E$ over the Indian subcontinent and southern Asia as observed.

The change from the twentieth century to the twentyfirst century is an intensification of the ENSO-driven $P-E$ anomaly over the tropical Pacific, over the eastern equatorial Indian Ocean, in the SPCZ, and over the northern equatorial Atlantic Ocean. On the other hand, the change represents a weakening of $P-E$ variability (change of opposite sign to the twentieth-century pattern) over the southern equatorial Atlantic Ocean, on the northern flanks of the Pacific ITCZ region, and over the western equatorial Indian Ocean. Because of the much smaller subtropical and extratropical $P-E$ anomalies compared to their tropical counterparts and because of the importance of the variability over land, the twentiethcentury $P-E$ variability and twenty-first-century minus twentieth-century changes are shown for Africa and Asia in Fig. 4 and for North and South America in Fig. 5. The changes over Africa do not represent either a systematic weakening or strengthening but are quite spatially variable. An interesting feature is the development of a coherent ENSO-driven $P-E$ anomaly over the Sahel in the twenty-first century that did not exist in the prior century in the models (though it does in observations; Giannini et al. 2003). In East Africa, the dry-wet north-south dipole extending from Somalia to Mozambique intensifies significantly. Over central and northern India, Bangladesh, and Southeast Asia, the ENSO-driven $P-E$ anomaly intensifies to a statistically significant amount in the twenty-first century.

Over North America (Fig. 5), the ENSO-driven $P-E$ anomaly strengthens in southern Mexico, weakens from central Mexico to the southern United States and in the Pacific Northwest, but strengthens in Northern California and northeast North America. Although not clear in the figure, there is a modest northward extension of the region with negative $P-E$ during La Niña events. Very little of these changes over North America achieve even modest levels of statistical significance, and it is not clear that the models can reliably project changes at these spatial scales. For South America, ENSO-driven $P-E$ variability weakens in northeast Brazil and strengthens in southeast South America (SESA) between $20^{\circ}$ and $30^{\circ} \mathrm{S}$, with both differences being statistically significant at the 95\% level.

\section{a. Contribution of dynamic and thermodynamic mechanisms to changes in interannual ENSO-driven $P-E$ variability}

In many parts of the world, modeled $P-E$ variability intensifies as might be expected because of rising specific humidity, but this is not a universal result, with some areas of strong teleconnections to ENSO (e.g., southern 


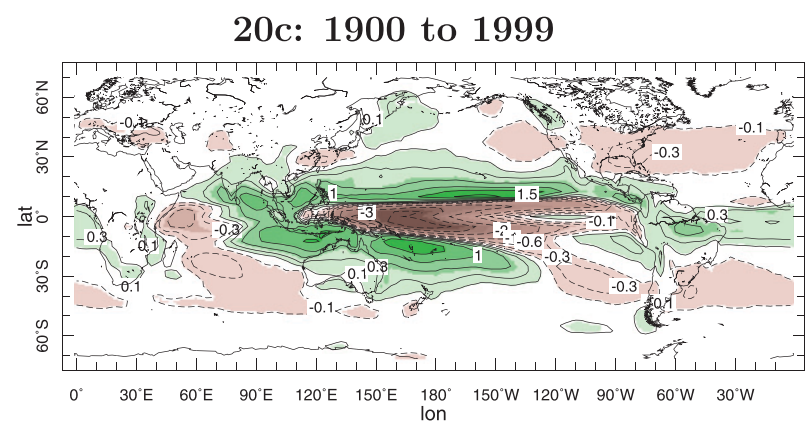

21c: 2000 to 2099

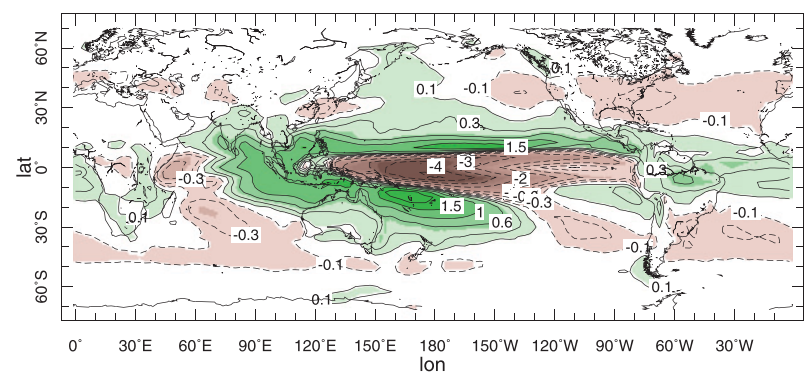

21c-20c:

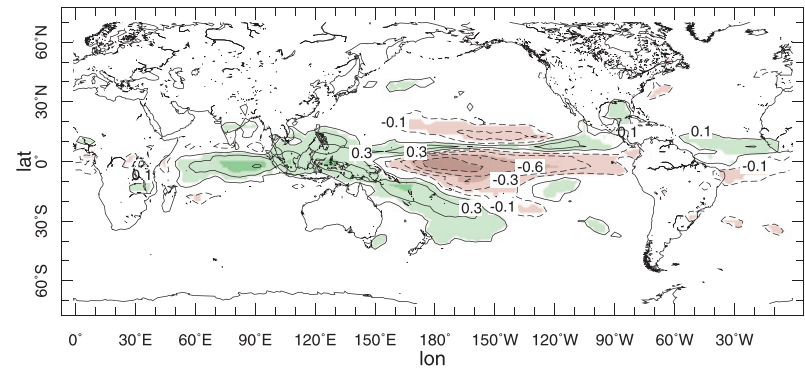

FIG. 3. The La Niña minus El Niño composite of $P-E\left(\mathrm{~mm} \mathrm{day}^{-1}\right)$ for the multimodel ensemble for (top) the twentieth century, (middle) the twenty-first century, and (bottom) the difference. Colors are added where the difference is significant at the $95 \%$ level.

North America and northeast Brazil) showing a weakening of interannual $P-E$ variability. Next, we examine the mechanisms responsible for the modeled ENSOdriven $P-E$ variability and its change between the two centuries. Figure 6 shows the contribution of the mean circulation dynamics $\delta \mathrm{MCD}$ term for the twentieth and twenty-first centuries and the difference. This is the term that gives rise to ENSO-driven $P-E$ anomalies as a consequence of changes in atmospheric circulation working on the climatological humidity. Comparing to Fig. 3, it is clear that the MCD term has the same global spatial pattern and amplitude as the $P-E$ variability itself, for both centuries. That is, ENSO-driven $P-E$ variability is to first order a consequence of circulation, not humidity, variability (SN12), and this remains the case under climate change. In most areas, the twentieth-century to twentyfirst-century change in $\delta \mathrm{MCD}$ amplifies the twentiethcentury pattern, with the exception of the western tropical Indian and equatorial Atlantic Oceans, where it contributes a weakening.

Figure 7 show the contribution of the thermodynamic term $\delta \mathrm{TH}$ to the ENSO-driven $P-E$ variability. This term is several times smaller than the $\delta \mathrm{MCD}$ term in both centuries. In regions of mean low-level divergence, such as over the equatorial Pacific cold tongue, negative specific humidity anomalies during La Niña events, as well as positive anomalies during El Niño events, create a tendency to positive $P-E$ anomalies that weakly offset the $\delta \mathrm{MCD}$ contribution. An opposite-sign $\delta \mathrm{TH}$ contribution is over the western equatorial Pacific, where the mean lowlevel flow is convergent.

The change from the twentieth century to the twentyfirst century of the $\delta \mathrm{TH}$ term is extremely small (Fig. 7, bottom) (although it has the same sign as its twentiethcentury pattern, as expected from rising humidity) and will be discussed no more. On the other hand, the change in the pattern of ENSO-driven $P-E$ variability is almost entirely accounted for by the change in the $\delta \mathrm{MCD}$ contribution (Fig. 6, bottom). That is, just as circulation variability creates the global pattern of $P-E$ variability, so it is that changes in the circulation variability contribution cause the twentieth-century to twenty-firstcentury change. Of course, there will be a thermodynamic contribution to the change in $\delta \mathrm{MCD}$, as unchanged circulation anomalies become more effective in a moistening atmosphere. Hence, we next break down $\delta \mathrm{MCD}$ into its two constituent parts as in Eqs. (14)-(16).

Figure 8 shows the change in the $\delta \mathrm{MCD}$ term and contributions to this from the change in specific humidity, working with the unchanged circulation variability, and the change in circulation variability, working with the unchanged specific humidity. Reassuringly so, the term that reflects the impact of rising specific humidity simply acts to amplify the $\delta \mathrm{MCD}$ term and hence the $P-E$ variability. However, the term that reflects the change in ENSO-driven circulation variability is in many locations as large as or larger than the term with the mean humidity increase. For example, this term creates the north-south dipole in the change in $P-E$ variability over the tropical Atlantic and contributes significantly to the change in $P-E$ variability over the Indian Ocean. It also adds to the impact of rising humidity by increasing the strength of the negative $\delta \mathrm{MCD}$ term over the central equatorial Pacific Ocean and of the positive $\delta \mathrm{MCD}$ term over the Maritime Continent region. In the northern Pacific ITCZ region, the change in the $\delta \mathrm{MCD}$ term is negative, which represents a weakening of the $\delta \mathrm{MCD}$ term, and this is 


\section{$20^{\text {th }}$ C ENSO-driven P-E variability}
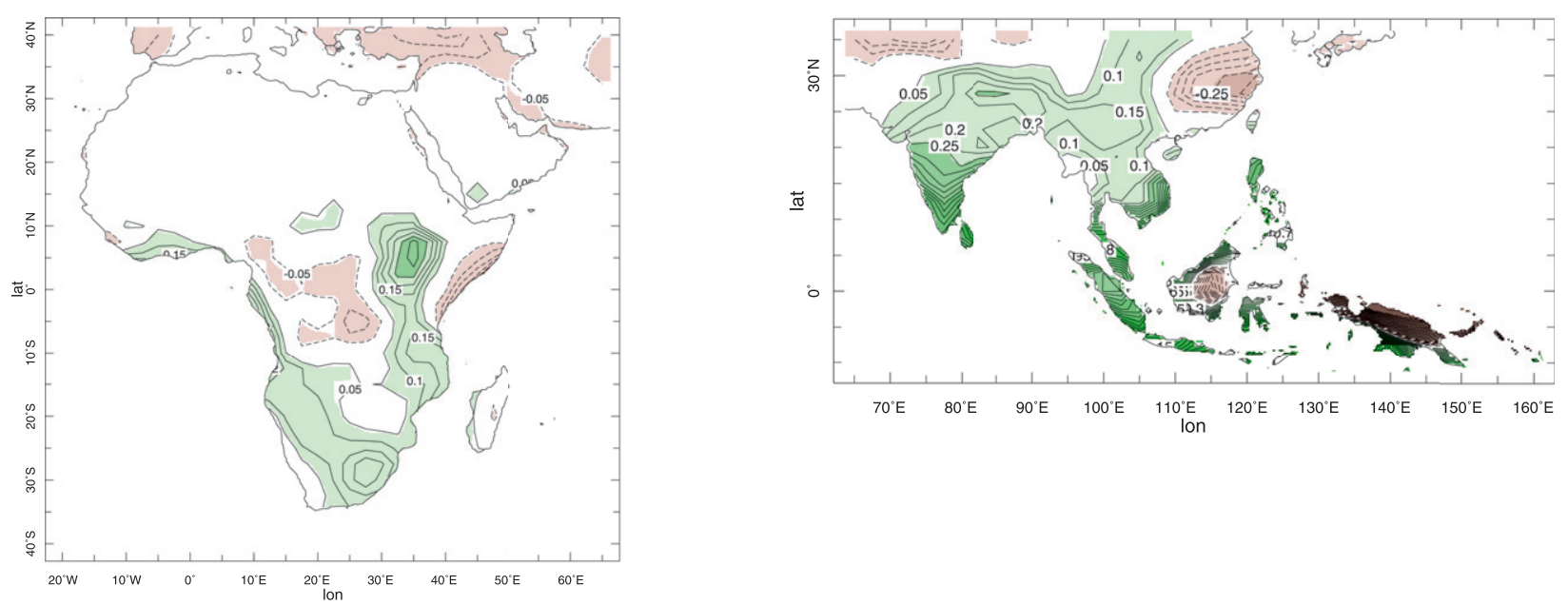

\section{$20^{\text {th }} \mathbf{C}$ to $21^{\text {st }} \mathbf{C}$ change}
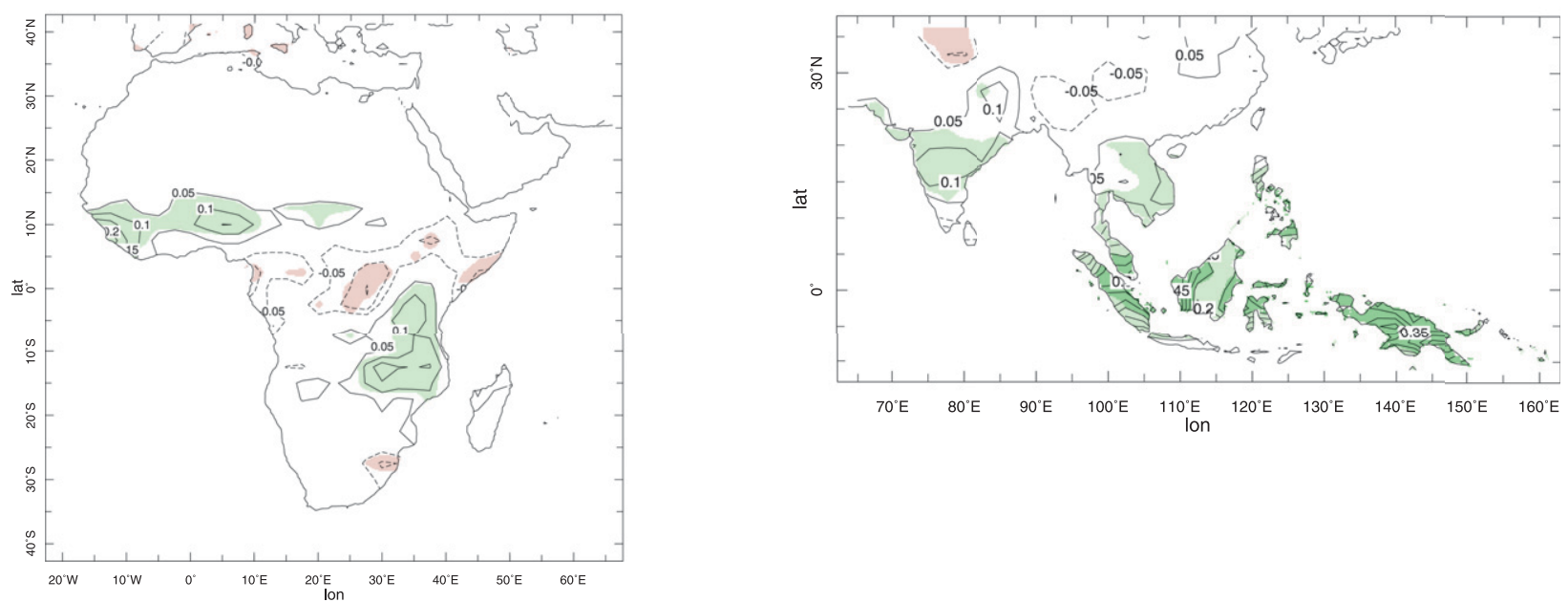

FIG. 4. As in Fig. 3, but shown just for Africa and south Asia. Only regions where the difference is significant at the $95 \%$ level are colored.

caused by a weakening of the circulation anomaly. In contrast, in the South Pacific convergence zone the change in the $\delta \mathrm{MCD}$ term is a strengthening of the contribution to positive $P-E$ anomalies, and this is caused by a strengthening of the circulation variability.

\section{b. Relationship of changes in the dynamic} contribution to ENSO-driven interannual $P-E$ variability to changes in vertical velocity variability

So far, we have shown that ENSO-driven $P-E$ variability is dominated by circulation variability working on the climatological specific humidity and that the twentiethcentury to twenty-first-century rise in humidity creates a tendency to more extreme $P-E$ variability but that this can be interfered with by changes in the circulation variability itself. The importance of vertical motion in determining the horizontal moisture convergence and divergence anomalies that control $P-E$ anomalies suggests that we may be able to better understand the changes in the dynamic contribution to $P-E$ variability by examining vertical velocity variability. Figure 9 shows the MEM ENSO-driven variability of the vertical pressure velocity at $700 \mathrm{mb}$ for the twentieth and twenty-first centuries and the difference. The vertical pressure velocity has been multiplied by -1 so that positive is upward and so that the color scale matches that for $P-E$ (green is wet, upward motion and brown is dry, downward motion). The difference is also plotted in contours 


\section{$20^{\text {th }}$ C ENSO-driven P-E variability}
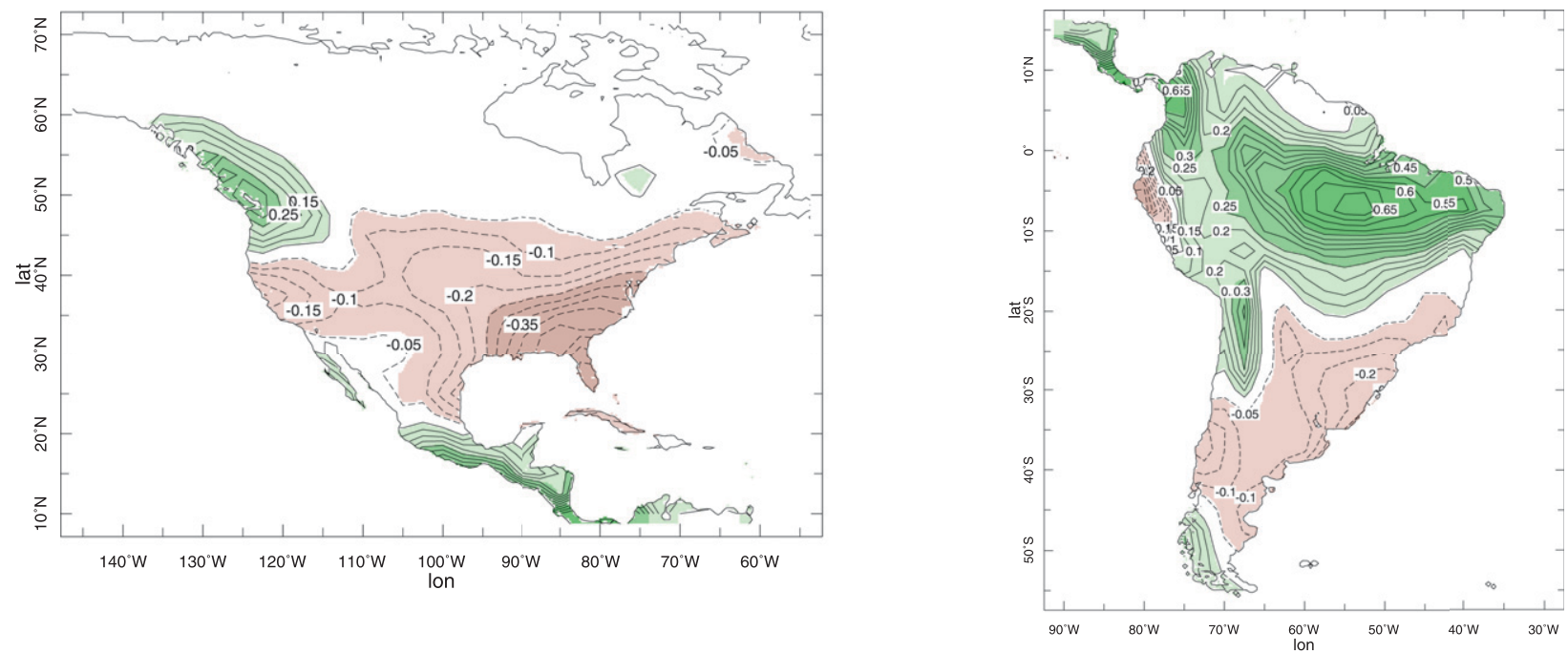

\section{$20^{\text {th }} \mathbf{C}$ to $21^{\text {st }} \mathbf{C}$ change}
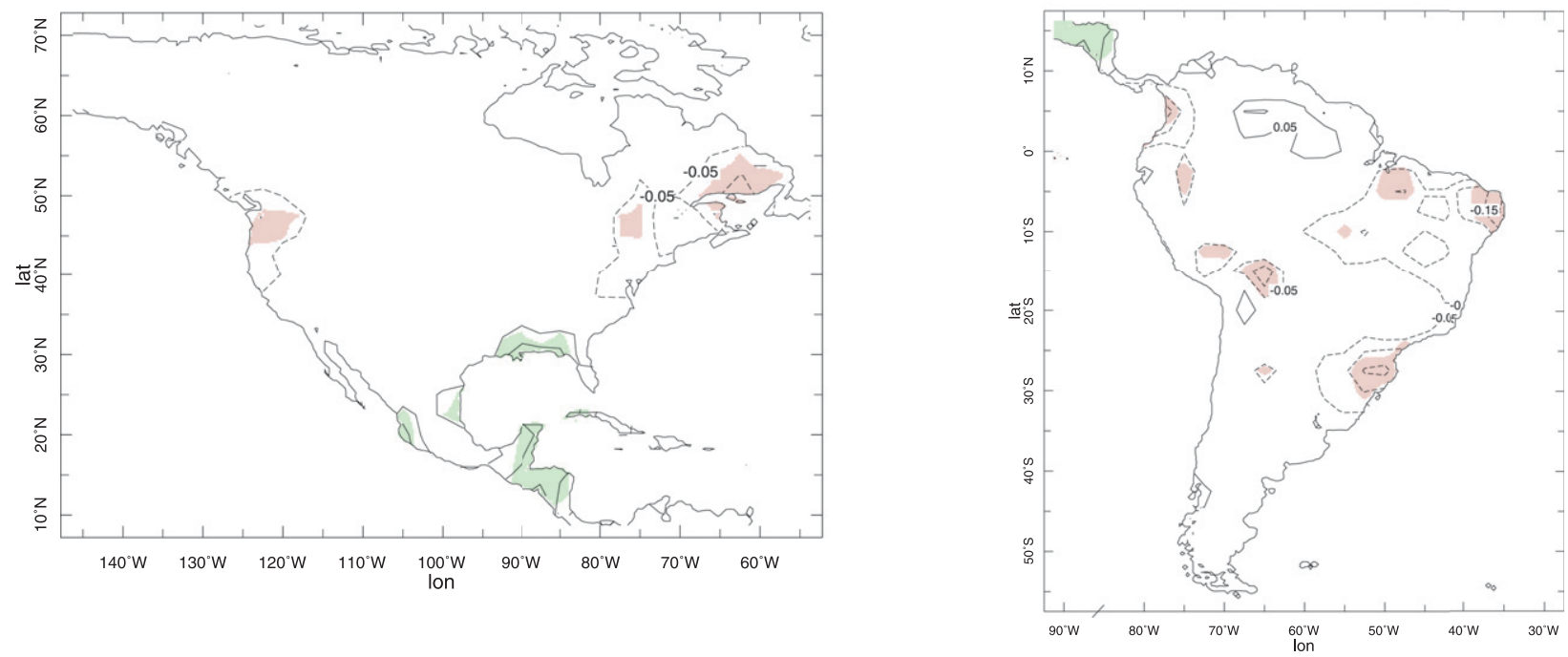

FIG. 5. As in Fig. 3, but shown just for North and South America. Only regions where the difference is significant at the $95 \%$ level are colored.

on top of the twentieth-century values in colors (Fig. 9, bottom).

During model La Niñas, relative to El Niños, there is descending motion across the equatorial Pacific Ocean, with ascending motion in the ITCZ region to the north and the SPCZ region to the southwest and also over the Maritime Continent-eastern Indian Ocean region. There is also widespread descent in the subtropics to midlatitudes, including over southern North America. These model patterns are quite similar to observed patterns and are related to widespread subtropical to midlatitude drought during La Niñas (Seager et al. 2003, 2005; Seager 2007). The change in vertical velocity variability from the twentieth century to the twenty-first century has some character of a reduction in amplitude: for example, in the north Pacific ITCZ region, over the west Pacific warm pool, and over the equatorial Atlantic Ocean. Elsewhere, increases in amplitude occur over the central equatorial Pacific Ocean (indicative of an eastward shift of ENSO-forced vertical velocity variability), over the 


\section{0c: 1900 to 1999}

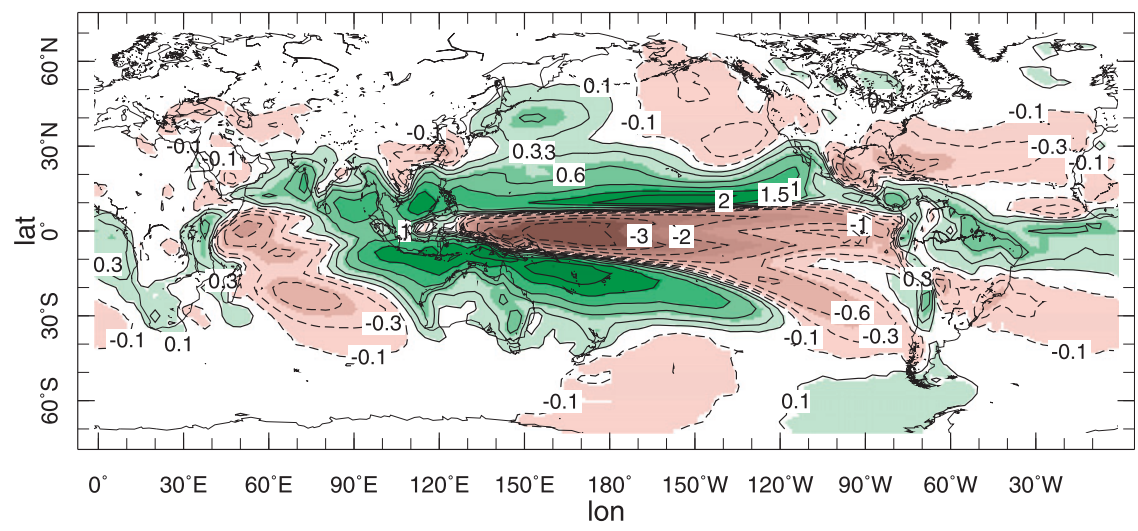

\section{1c: 2000 to 2099}

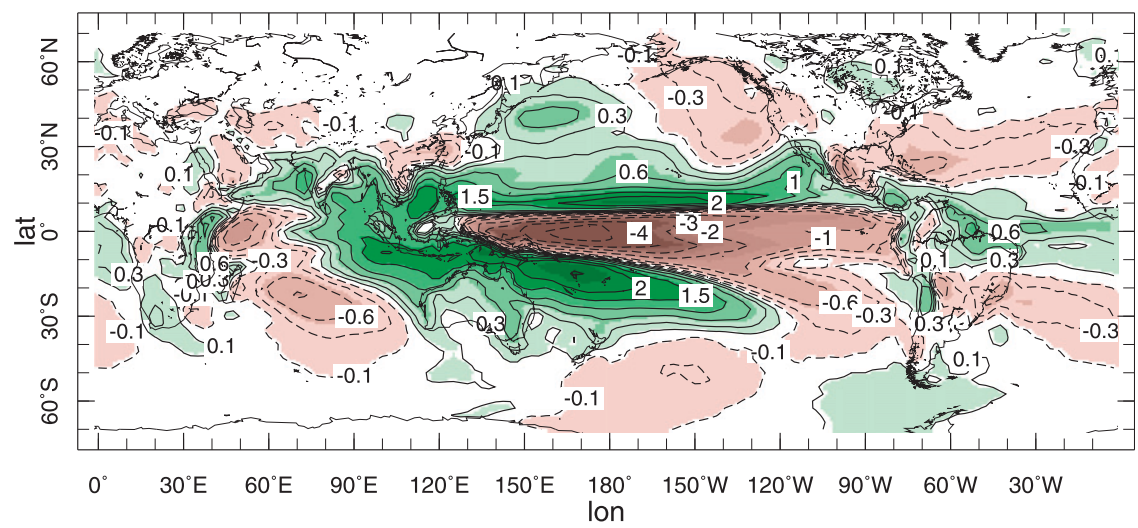

\section{1c-20c(contours), 20c(colors)}

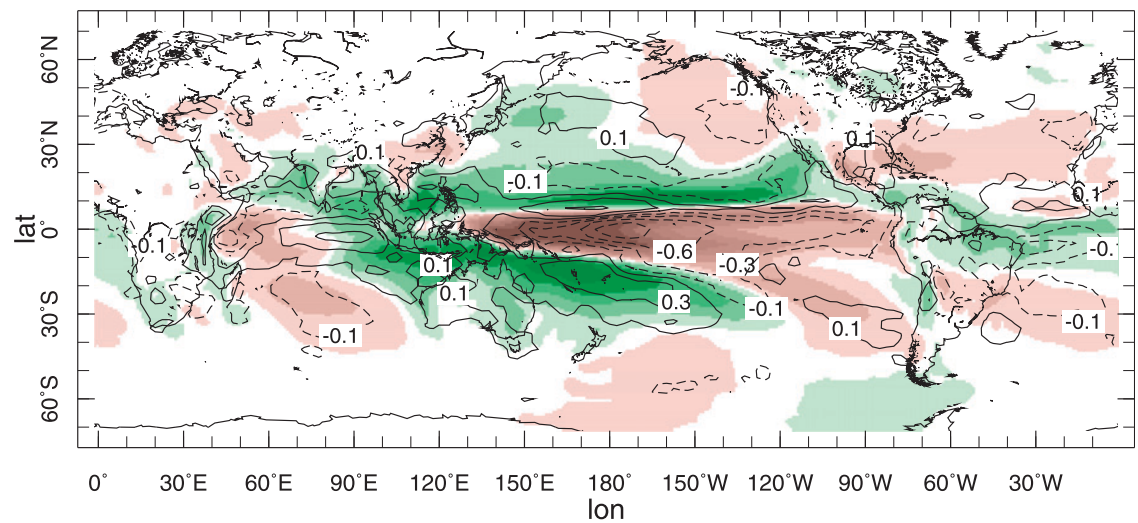

FIG. 6. The La Niña minus El Niño composite of the mean circulation dynamics $(\delta \mathrm{MCD})$ contribution to $P-E$ variability for the multimodel ensemble for (top) the twentieth century, (middle) the twenty-first century, and (bottom) the difference. Units are mm day ${ }^{-1}$. 


\section{0c: 1900 to 1999}

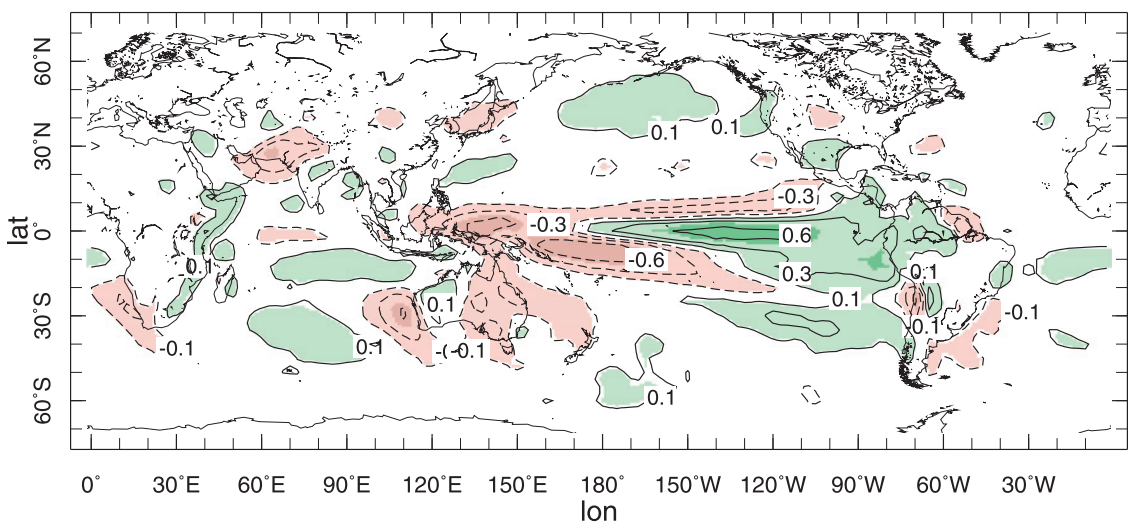

21c: 2000 to 2099

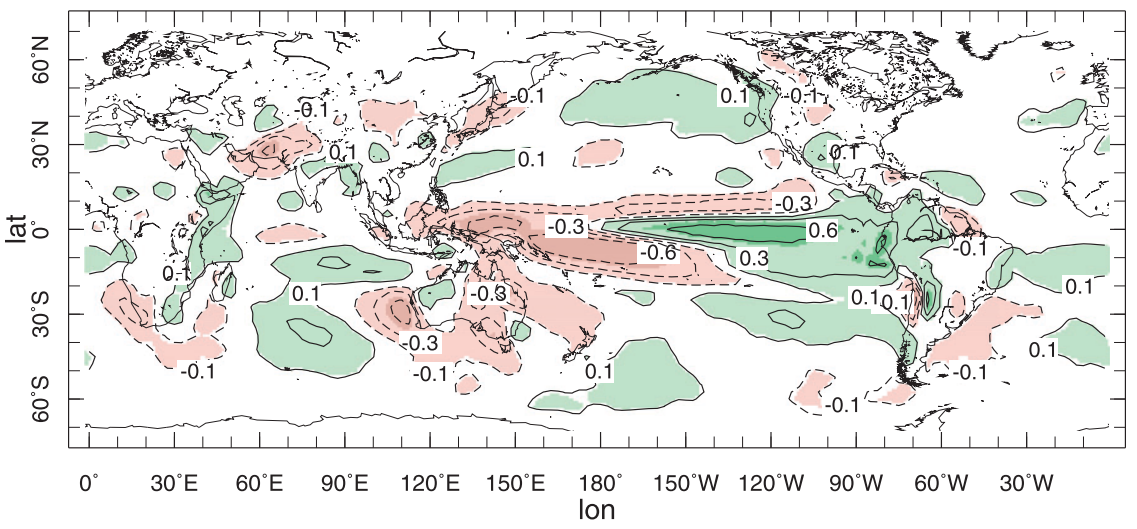

\section{$21 \mathrm{c}-20 \mathrm{c}$ (contours), 20c(colors)}

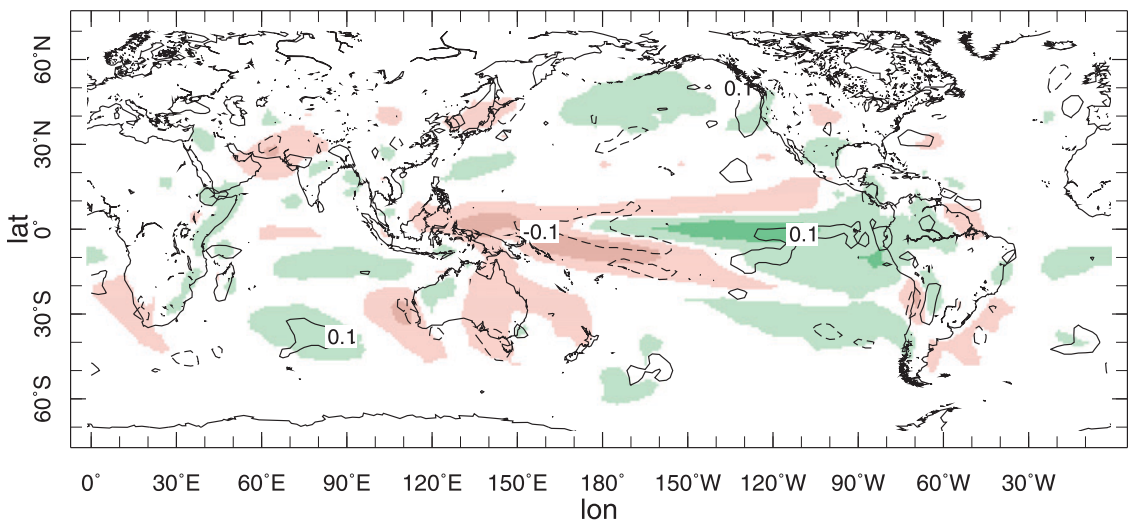

FIG. 7. As in Fig. 6, but for the thermodynamic $(\delta \mathrm{TH})$ contribution to the La Niña minus El Niño $P-E$ composite. Units are $\mathrm{mm} \mathrm{day}^{-1}$.

Atlantic at about $10^{\circ} \mathrm{N}$, and over the eastern equatorial Indian Ocean. There is also a notable weakening of the amplitude of vertical velocity variability over southern North America.
The spatial pattern of change in vertical velocity variability is very similar to that of the variable circulation contribution to the $\delta \mathrm{MCD}$ term (Fig. 8, bottom), indicating that the latter is closely controlled by the 

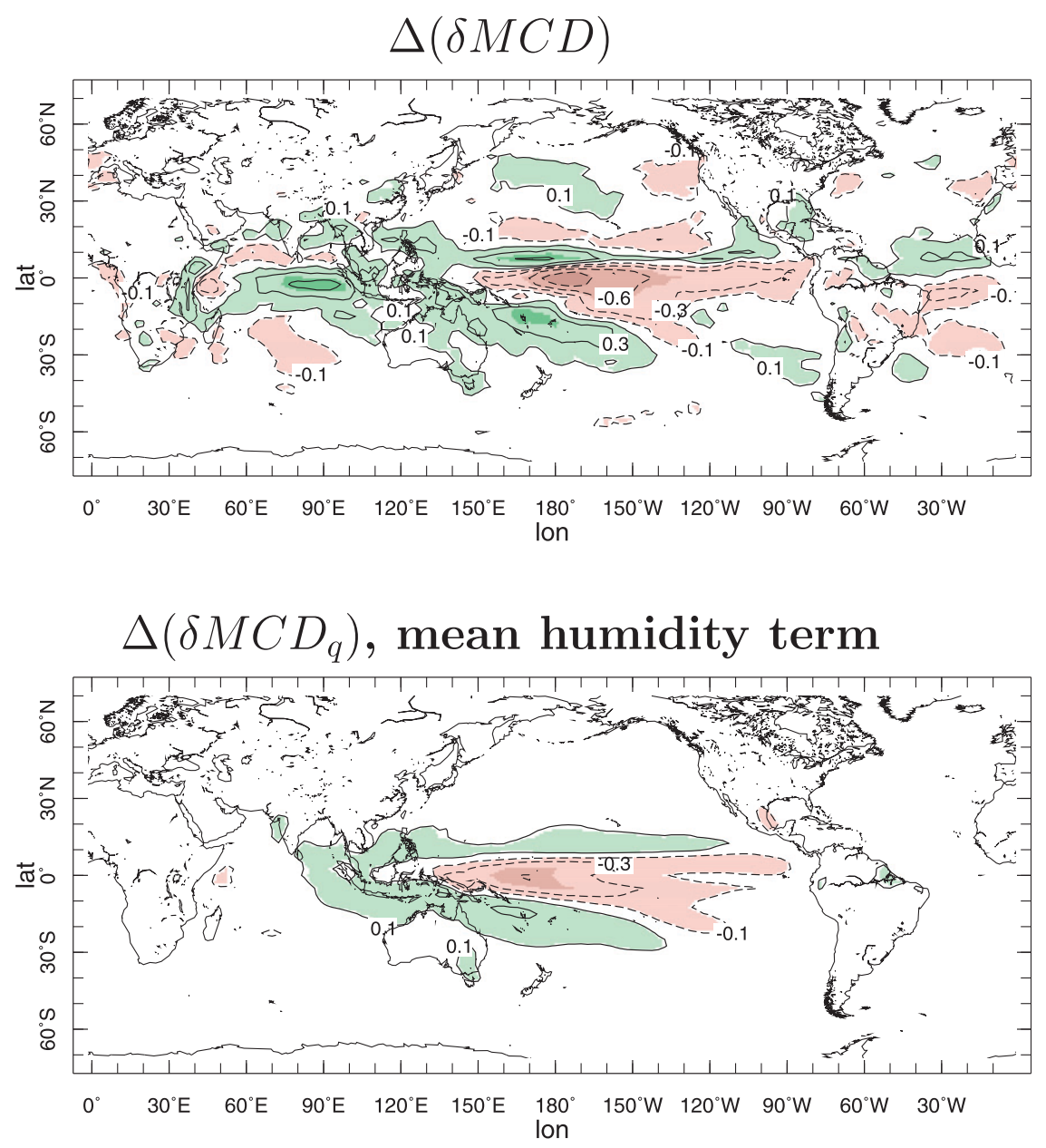

\section{$\triangle\left(\delta M C D_{u}\right)$, variable circulation term}

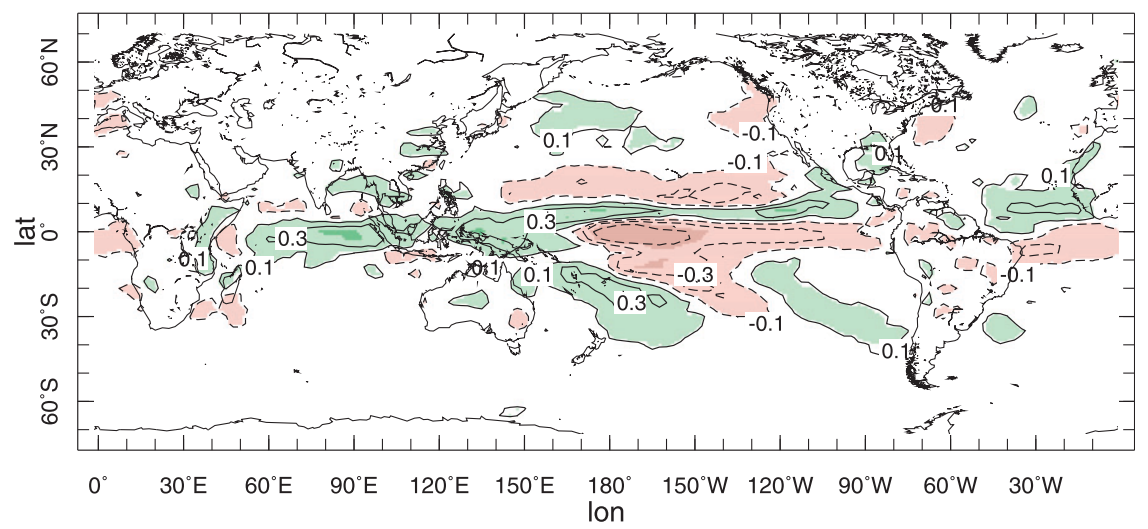

FIG. 8. (top) The twenty-first-century minus twentieth-century change in the La Niña minus El Niño composite of the mean circulation dynamics ( $\delta \mathrm{MCD}$ ) contribution to $P-E$ variability for the multimodel ensemble and the contributions to it from (middle) the change in mean specific humidity and (bottom) the change in circulation variability. Units are mm day ${ }^{-1}$. 

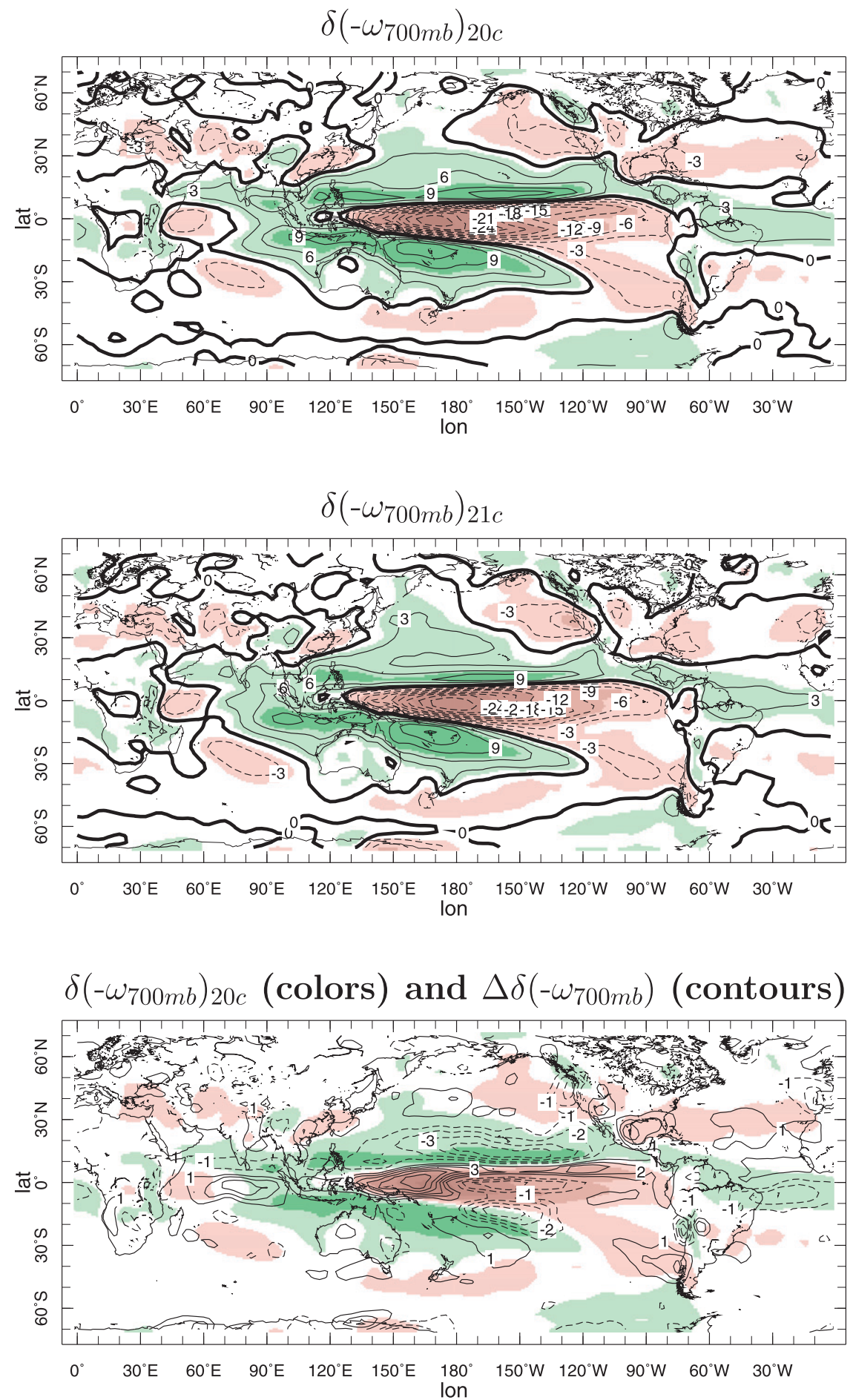

FIG. 9. The (top) twentieth- and (middle) twenty-first-century La Niña minus El Niño composite of the 700-mb vertical pressure velocity multiplied by -1 for the multimodel ensemble and (bottom) the twenty-first-century minus twentieth-century difference (contours) plotted on top of the twentieth-century values (colors). Units are mb day ${ }^{-1}$. 
former. Given the strength of the contribution of change in circulation variability to the change in $P-E$ variability, the pattern of the change in vertical velocity variability is also quite similar to the pattern of the change in the total $\delta$ MCD term (Fig. 6, bottom).

It has been well established that the mean tropical circulation weakens as a consequence of global warming (Vecchi and Soden 2007), which can be explained in terms of energy balance constraints when specific humidity rises at a faster rate than surface evaporation (Betts and Ridgway 1989; Betts 1990, 1998; Held and Soden 2006). It might be thought that these same constraints would cause ENSO-driven vertical motion anomalies to weaken. Because teleconnection patterns to higher latitudes are fundamentally driven by uppertropospheric divergent wind anomalies (Sardeshmukh and Hoskins 1988; Trenberth et al. 1998), this could then lead to weaker forced Rossby wave trains and associated circulation anomalies. This however does not appear to be generally the case. Circulation variability instead changes in a more complex manner probably related to changes in the location of ENSO SST anomalies, the basic state that impacts both the Rossby wave source and the flow through which Rossby waves propagate and the transient eddy-mean flow interaction that strongly controls the extratropical wave response to ENSO (Hoerling and Ting 1994; Seager et al. 2010b; Harnik et al. 2010).

\section{Conclusions}

We have investigated whether global warming leads to an increase in the amplitude of interannual $P-E$ variability. This might be expected because of the increase in water vapor content of the atmosphere, which has been shown previously to cause an increase in climatological precipitation extremes with wet areas getting wetter and dry areas getting drier, a phenomenon also known as "rich get richer" (Held and Soden 2006; Chou et al. 2009; Seager et al. 2010c). This is examined using IPCC AR4CMIP3 simulations of the twentieth century and projections of the twenty-first century with the A1B emissions scenario, evaluating variability over each entire century. The results are as follows:

- As expected, the amplitude of total interannual $P-E$ variability increases almost everywhere across the planet. The highest increases, of $40 \%$ or more, are over the equatorial Pacific and at high latitudes. Increases of around $10 \%$ are more common elsewhere. Over the eastern subtropical Pacific Ocean, over the subtropical Atlantic, and over southwestern North America $P-E$ variability actually weakens. This spatial pattern is somewhat akin to the pattern of climatological $P-E$ change. It is also similar to that of the change in lowertropospheric moisture content but is more accentuated. In regions where the $P-E$ variance increases less than the mean specific humidity, it can be explained because of a near-global decrease in the amplitude of (annual and monthly mean) vertical velocity variability. Vertical velocity variance does increase over the equatorial Pacific and at polar latitudes, all regions of maximum increases in $P-E$ variance.

- In the tropical Pacific region, ENSO-driven $P-E$ variance also increases from the twentieth century to the twenty-first century by as much as a quarter. Elsewhere, changes in ENSO-driven variance are more complex. In the Indian subcontinent, Southeast Asia, and Indonesia, there is also an increase. Over eastern Africa, the northsouth dry-wet dipole with centers in Somalia-Ethiopia and Kenya-Mozambique strengthens. A stronger Sahel variability also develops. Over Central America, ENSOdriven variance increases, whereas over southern North America it decreases but not by a statistically significant amount. Northeast Brazil experiences a statistically significant weakening of ENSO-driven variance.

- ENSO-driven $P-E$ variance is overwhelmingly dominated by circulation anomalies working with the climatological-mean specific humidity. That is, it is "dynamics dominated" with anomalies in the mean flow being primarily responsible. As specific humidity rises in a warmer atmosphere, it would be expected that this mean circulation contribution to $P-E$ anomalies would strengthen. This is indeed the case. However, the contribution from the change in the ENSO-driven circulation anomalies is just as important. It is this term that allows ENSO-driven $P-E$ variance to decrease in amplitude, such as over the equatorial Atlantic Ocean, northeast Brazil, and southern North America.

- The change in the contribution of circulation variability to ENSO-driven $P-E$ variability is closely matched by the change in ENSO-driven 700-mb vertical velocity variability. Over the equatorial Pacific Ocean, there is an eastward shift of the longitude of maximum vertical velocity variance. This, however, does not translate into an eastward shift of the longitude of maximum $P-E$ variance because the influence of the specific humidity increase is centered west of the date line. Over the tropical Atlantic Ocean, La Niña events are associated with equatorially symmetric anomalous ascent. In the twenty-first century, this ascent anomaly weakens south of the equator but strengthens north of the equator, creating the dipole of change in ENSO-driven $P-E$ anomaly.

To summarize, on the interannual time scale the widely held belief that hydroclimate variability intensifies 


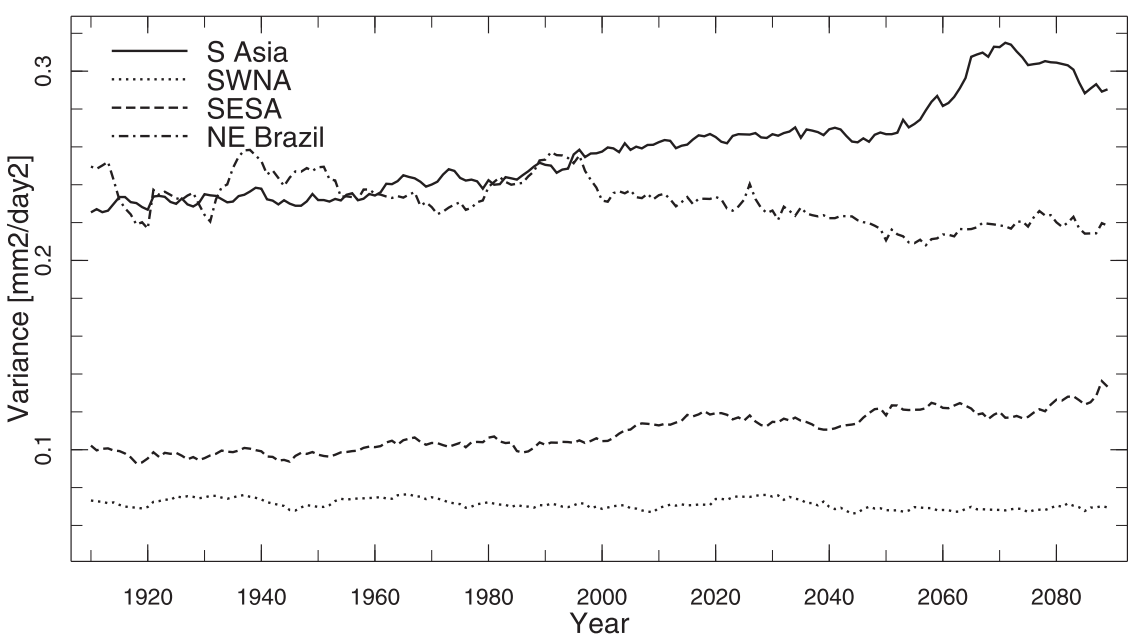

FIG. 10. The variance of $P-E$ calculated in running 20-yr windows for 1900-2100 with data detrended within the window for each grid point of each model and then averaged across models and across space for south Asia, SWNA, northeast Brazil, and SESA. More details in text. Units are $\left(\mathrm{mm} \text { day }^{-1}\right)^{2}$.

as a result of global warming is confirmed to be true, according to the models participating in CMIP3 and assessed by IPCC AR4. Only in a few, mostly subtropical areas of the globe, does the interannual variability of $P-$ $E$ weaken. The change in $P-E$ variability should be underway if the models are correct. Figure 10 shows time series of the spatial averages of total variance of $P-E$ evaluated in 20-yr running windows (with data detrended within the window) for south Asia $\left(0^{\circ}-25^{\circ} \mathrm{N}, 65^{\circ}-110^{\circ} \mathrm{E}\right)$, southwest North America (SWNA; $25^{\circ}-40^{\circ} \mathrm{N}, 125^{\circ}-$ $\left.95^{\circ} \mathrm{W}\right)$, northeast Brazil $\left(20^{\circ}-5^{\circ} \mathrm{S}, 60^{\circ}-35^{\circ} \mathrm{W}\right)$, and southeast South America $\left(40^{\circ}-20^{\circ} \mathrm{S}, 65^{\circ}-35^{\circ} \mathrm{W}\right)$, using land areas only. Increased variances for southern Asia and southeast South America in the early part of the current century are marked, but the decreases in northeast Brazil and southwest North America are more modest. The dominant global mode of hydroclimate variability is ENSO, which is also the only mode to possess proven predictability on the seasonal to interannual time scale. ENSO-driven $P-E$ variability in the models does not increase uniformly and in some places weakens, because of changes in the ENSO-driven circulation variability.

It is not understood why the total and ENSO-driven vertical velocity anomalies change in the way they do. However, it is not fully understood why the observed or modeled twentieth-century ENSO-driven vertical motion velocities have the spatial patterns and magnitudes that they do (see Seager et al. 2005). Hence, it seems premature to explain the twentieth-century to twenty-first-century change in vertical velocity variability. More work is needed to better understand the coupling between dynamics and thermodynamics that determines circulation and precipitation variability and how this depends on the changing mean climate. Here, we just note that, in considering the primary potentially predictable component of $P-E$ variability, caution is in order in anticipating how it will change. Because it is caused by circulation variability, changes in intratropical and tropical to extratropical teleconnections can cause altered locations and amplitudes of ENSO-driven $P-E$ anomalies. However, it must be remembered that ENSO itself and the regional details of ENSO-driven $P-E$ anomalies are not always well represented in the model simulations of the current climate, and modeled changes in these in response to rising greenhouse gases contain uncertainty. However, in some important places, such as most of southern Asia, the models do suggest that total hydroclimate variability and its ENSO-driven component strengthen from the twentieth to the twentyfirst century. This is one of many regions of the world where natural variability of climate already wreaks havoc in terms of floods, droughts, crop failures, food shortages, and loss of human life. According to the model results presented here, quite apart from any change in mean climate, the variability of climate, no longer natural but a mixed hybrid of internal atmosphere-ocean variability and human-induced climate change, will only become more extreme amplifying stress on societies that are already hard pressed to cope with current-day, more-muted variability.

Acknowledgments. This work was supported by NOAA Grants NA08OAR4320912 and NA10OAR4320137 and 
NSF Grant ATM-08-04107. LV was supported as a summer undergraduate intern at Lamont by NSF Grant OCE06-49024. The comments and advice of Lisa Goddard and Arthur Greene and the Global Decadal Hydroclimate (GloDecH) group at Lamont and Columbia were essential to the progress of this work.

\section{REFERENCES}

Anyah, R. O., C. P. Weaver, G. Miguez-Macho, Y. Fan, and A. Robock, 2008: Incorporating water table dynamics in climate modeling: 3 . Simulated groundwater influence on coupled land-atmosphere variability. J. Geophys. Res., 113, D07103, doi:10.1029/2007JD009087.

Betts, A. K., 1990: Greenhouse warming and the tropical water vapor budget. Bull. Amer. Meteor. Soc., 71, 1464-1465.

1998: Climate-convection feedbacks: Some further issues. Climatic Change, 39, 35-38.

— , and W. Ridgway, 1989: Climatic equilibrium of the atmospheric convective boundary layer over a tropical ocean. J. Atmos. Sci., 46, 2621-2641.

Cattiaux, J., R. Vautard, C. Cassou, P. Yiou, V. Masson-Delmonte, and F. Codron, 2010: Winter 2010 in Europe: A cold event in a warming climate. Geophys. Res. Lett., 37, L20704, doi:10.1029/ 2010 GL044613.

Chou, C., J. D. Neelin, C. Chen, and J. Tu, 2009: Evaluating the "rich-get-richer" mechanism in tropical precipitation change under global warming. J. Climate, 22, 1982-2005.

Dole, R., and Coauthors, 2011: Was there a basis for anticipating the 2010 Russian heat wave? Geophys. Res. Lett., 38, L06702, doi:10.1029/2010GL046582.

Giannini, A., R. Saravanan, and P. Chang, 2003: Oceanic forcing of Sahel rainfall on interannual to interdecadal timescales. Science, 302, 1027-1030.

Groisman, P. Ya., R. W. Knight, D. R. Easterling, T. R. Karl, G. C. Hegerl, and V. N. Razuvaev, 2005: Trends in intense precipitation in the climate record. J. Climate, 18, 1326-1350.

Harnik, N., R. Seager, N. Naik, M. Cane, and M. Ting, 2010: The role of linear wave refraction in the transient eddy-mean flow response to tropical Pacific SST anomalies. Quart. J. Roy. Meteor. Soc., 136, 2132-2146.

Held, I. M., and B. J. Soden, 2006: Robust responses of the hydrological cycle to global warming. J. Climate, 19, 5686-5699.

Hoerling, M. P., and M. Ting, 1994: Organization of extratropical transients during El Niño. J. Climate, 7, 745-766.

Huang, H., R. Seager, and Y. Kushnir, 2005: The 1976/77 transition in precipitation over the Americas and the influence of tropical SST. Climate Dyn., 24, 721-740.

Koster, R., and Coauthors, 2004: Regions of strong coupling between soil moisture and precipitation. Science, 305, 1138-1140.

Lo, M.-H., and J. S. Famiglietti, 2011: Precipitation response to land subsurface hydrologic processes in atmospheric general circulation models. J. Geophys. Res., 116, D05107, doi:10.1029/ 2010JD015134.

Meehl, G., C. Covey, T. Delworth, M. Latif, B. McAvaney, J. F. B. Mitchell, R. J. Stouffer, and K. E. Taylor, 2007: The WCRP CMIP3 multimodel dataset: A new era in climate change research. Bull. Amer. Meteor. Soc., 88, 1383-1394.

Neelin, J. D., M. Munnich, H. Su, J. E. Meyerson, and C. E. Holloway, 2006: Tropical drying trends in global warming models and observations. Proc. Natl. Acad. Sci. USA, 103, 61106115.

O'Gorman, P., and T. Schneider, 2009: The physical basis for increases in precipitation extremes in simulations of 21stcentury climate change. Proc. Natl. Acad. Sci. USA, 106, $14773-14777$.

Pall, P., T. Ainu, D. A. Stone, P. A. Stott, T. Nozawa, A. G. J. Hilberts, D. Lohmann, and M. R. Allen, 2011: Anthropogenic greenhouse gas contribution to flood risk in England and Wales in autumn 2000. Nature, 470, 382-386.

Sarachik, E. S., 2010: The tools of adaptation. Proc. Second Int Conf. on Climate, Sustainability and Development in SemiArid Regions, Fortaleza, Brazil. [Available online at http:// icid18.org/.]

Sardeshmukh, P. D., and B. J. Hoskins, 1988: The generation of global rotational flow by steady idealized tropical divergence. J. Atmos. Sci., 45, 1228-1251.

Seager, R., 2007: The turn-of-the-century North American drought: Dynamics, global context, and prior analogues. J. Climate, 20, 5527-5552.

- and N. Naik, 2012: A mechanisms-based approach to detecting recent anthropogenic hydroclimate change. J. Climate, 25, 236-261.

-, N. Harnik, Y. Kushnir, W. Robinson, and J. Miller, 2003: Mechanisms of hemispherically symmetric climate variability. J. Climate, 16, 2960-2978.

, W. A. Robinson, Y. Kushnir, M. Ting, H. P. Huang, and J. Velez, 2005: Mechanisms of ENSO-forcing of hemispherically symmetric precipitation variability. Quart. J. Roy. Meteor. Soc., 131, 1501-1527.

_ , and Coauthors, 2007: Model projections of an imminent transition to a more arid climate in southwestern North America. Science, 316, 1181-1184.

-, Y. Kushnir, J. Nakamura, M. Ting, and N. Naik, 2010a: Northern hemisphere winter snow anomalies: ENSO, NAO and the winter of 2009/10. Geophys. Res. Lett., 37, L14703, doi:10.1029/2010GL043830.

_ , N. Naik, M. A. Cane, N. Harnik, M. Ting, and Y. Kushnir, 2010b: Adjustment of the atmospheric circulation to tropical Pacific SST anomalies: Variability of transient eddy propagation in the Pacific-North America sector. Quart. J. Roy. Meteor. Soc., 136, 277-296.

, - _ and G. Vecchi, 2010c: Thermodynamic and dynamic mechanisms for large-scale changes in the hydrological cycle in response to global warming. J. Climate, 23, 4651-4668.

Seneviratne, S. I., D. Luthi, M. Litschi, and C. Schar, 2006: Landatmosphere coupling and climate change in Europe. Nature, 443, 205-209.

Trenberth, K., G. W. Branstator, D. Karoly, A. Kumar, N. Lau, and C. Ropelewski, 1998: Progress during TOGA in understanding and modeling global teleconnections associated with tropical sea surface temperature. J. Geophys. Res., 103, 14 291-14 324

_ A. Dai, E. M. Rasmussen, and D. B. Parsons, 2003: The changing character of precipitation. Bull. Amer. Meteor. Soc., 84, 1205-1217.

Vecchi, G. A., and B. J. Soden, 2007: Global warming and the weakening of the tropical circulation. J. Climate, 20, 43164340.

Webster, P. J., V. E. Toma, and H.-M. Kim, 2011: Were the 2010 Pakistan floods predictable? Geophys. Res. Lett., 38, L04806, doi:10.1029/2010GL046346. 